\title{
Assignment Research Calculator Designing and implementing a customized product to reach your students
}

$\mathbf{T}$ he original Assignment Calculator from the University of Minnesota is a free open-source tool which helps students manage time and organize the steps of a research project. ${ }^{1}$ It provides a schedule and timeline for each step, and includes tips and outside links to more information. The head of instruction and outreach services in the Henry Madden Library recognized the value of this popular tool, but felt we could expand on its potential for students and faculty here at California State University-Fresno. We accomplished this by tailoring it to our own library and campus resources, staff and services, thus making it more appropriate to the needs of our students.

The Assignment Research Calculator

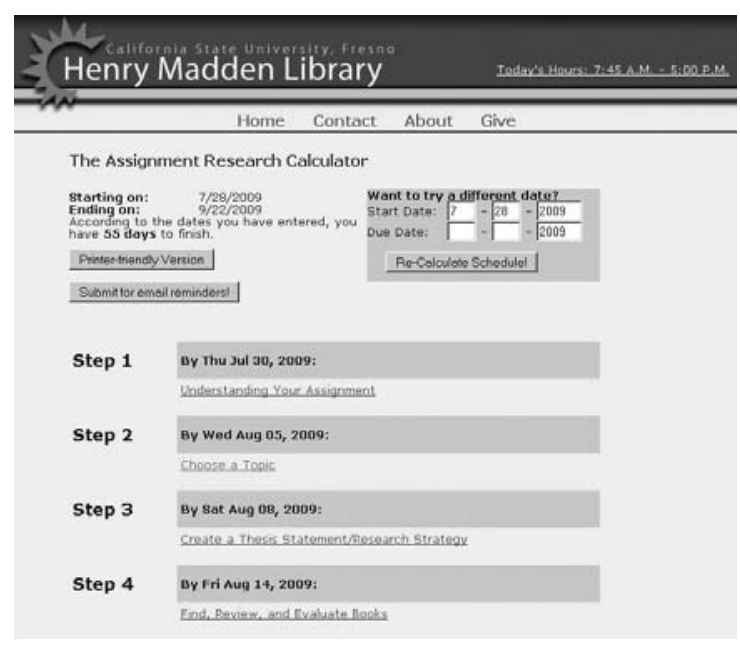

The Henry Madden Library's Assignment Research Calculator. understanding of the research and writing process, students are better prepared to participate in the community of scholars in higher education.

\section{Creating our own ARC}

We drew on our years of professional experience working with students as reference and instruction librarians to begin assessing what we wanted to cover. The head of instruction and outreach services had taught University 1 (a First-Year Experience course) several times, and had an additional perspective on the needs of these students, such as improving skills in time management, understanding university life, researching information, and writing.

Every campus has a unique student body, and we looked carefully at demographic information about the students at our campus, including data such as ethnicity, retention and graduation rates, first-generation status, income, full-/ part-time status, in order to have a better understanding of who we are reaching with

Monica Fusich is head of instruction and outreach services at California State University-Fresno, e-mail: monicaf@scufresno. edu, Jane Magee is reference and instruction librarian at California State University-Fresno, e-mail: jmagee@csufresno. edu, Elisabeth A. Thomas is research assistant/outreach librarian at San Jose State University, e-mail:elisabeth.thomas@sjsu.edu ○ 2009 Monica Fusich, Jane Magee, Elisabeth A. Thomas 
our instruction and how it might relate to current campus issues or goals. ${ }^{3}$

We also were aware that students want to use resources at times convenient to them, not necessarily during the traditional reference desk or faculty office hours. A tool such as the ARC is available $24 / 7$, in a format that is useful and appealing to them.

The open source code of the original Assignment Calculator creates a timeline based on dates the user provides. Each step in this timeline provides links to a variety of Web sites created by different colleges and universities. Instead of simply using that open source shell, the ARC team molded the framework into a customized product that would be more meaningful for our own students and faculty.

We did this by adapting the original tool, reducing and reworking the original steps to make them more meaningful to our students, writing our own content for each of the steps, and using screenshots and links for our own databases, Web sites, and resources. We incorporated more focus on the writing process in connection with the research students need to do for a paper or project, and provided lots of information on additional help through links to the reference desk, chat service, individual appointments with librarian subject liaisons, and to other campus services.

\section{Connecting with information literacy competency standards}

"Information literacy is the set of skills needed to find, retrieve, analyze and use information." ${ }^{4}$ We decided early on that these skills, as defined in detail in the "Information Literacy Competency Standards for Higher Education," would be used as the framework for building the most useful content for our students. We began our research process by investigating what others had done with online assignment calculators, but did not find much adaptation from the original open source tool. So we expanded our research to other forms of library tutorials, instruction modules, and interactive learning units that covered the concepts and competencies we wanted to include. We reviewed and evaluated a great deal of online material in order to get a clear idea of what was being written for college students in the areas of library instruction and writing. The material consulted during this evaluation is listed in a bibliography on our ARC Web site. ${ }^{6}$

We discussed this material at length and decided on what we felt were the most valuable instructional concepts for our students to learn from this tool. We reworked and renamed our steps based on these concepts, reduced the number from 12 to 10, composed our own content, and ultimately synched each step to the information literacy competency standards. By creating an outline of the standards, performance indicators and outcomes, and matching these directly with one or more ARC steps, we ensured that the ARC as a whole reflected all of these widely accepted standards. This same outline helped us in writing the content of the steps themselves, and enabled us to be sure that every competency was included in an appropriate section of the ARC.

A quote from the "Use of the Standards" section of the "Information Literacy Competency Standards for Higher Education" on the ACRL Web site illustrates the value of building the ARC the way we did. "The competencies presented here outline the process by which faculty, librarians and others pinpoint specific indicators that identify a student as information literate. Students also will find the competencies useful, because they provide students with a framework for gaining control over how they interact with information in their environment."7

An example of how we matched a standard with part of a step comes from Step 6, "Find, Review and Evaluate Web Sources."

The standard and outcomes:

Competency Standard Two: The information literate student accesses needed information effectively and efficiently.

Performance Indicator 1: The information literate student selects the most appropriate investigative methods or information retrieval systems for accessing the needed information. 


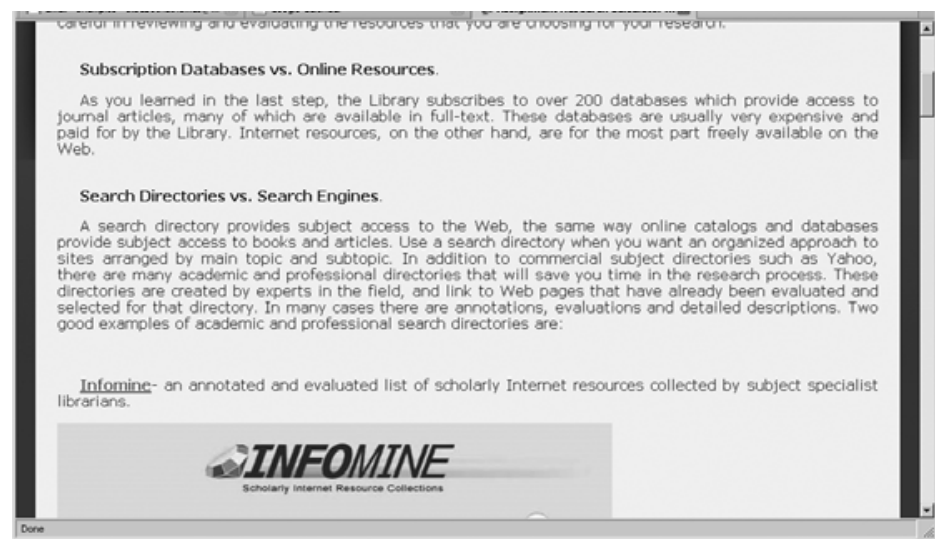

Screenshot from ARC.

Outcomes include: 2.1.c. Investigates the scope, content, and organization of information retrieval systems (step 4, 5, 6).

- Identifies the differences between freely available Internet search tools and subscription or fee-based databases (step 5, 6).

Our step:

Search Directories vs. Search Engines. A search directory provides subject access to the Web. Use a search directory when you want an organized approach to sites arranged by main topic and subtopic. In addition to commercial subject directories such as Yahoo, there are many academic and professional directories that will save you time in the research process. These directories are created by experts in the field, and link to Web pages that have already been evaluated and selected for that directory. In many cases there are annotations, evaluations and detailed descriptions.

Search engines. A Web search engine provides a keyword approach to finding information. You can search by keywords just like in the library catalog or library subscription databases. The most popular search engine is Google, of course. But there are others with different types of search interfaces that you may find interesting.

\section{Open source and technical issues}

In order to make the process of customizing the ARC more productive and efficient, it is important to have a representative from IT or a librarian with IT knowledge as part of the team. Downloading the open source code for the Assignment Calculator is just the first step. An individual with intermediate knowledge of PHP script and CSS is needed to generate the ARC and to calculate the time percentages allotted for the completion of each step. And if the ARC includes an email reminder feature for each step, scripting experience is also beneficial. The team should also have access to a portion of the server in order to make timely corrections, updates, and adaptations when necessary.

\section{Promoting ARC and assessing use}

Our ARC has been promoted through demonstrations by instruction librarians in classes, prominent placement on the library homepage, inclusion in many subject and course-specific LibGuides, orientations to new faculty, and through ads in the student newspaper.

We keep monthly statistics by unique visitors, number of visits, page hits, and hits by step. Our data show how heavily the ARC has been used since it was implemented, with highest use in March and May corresponding to midterms and the end of the semester (see graph 1).

One interesting finding was that the steps that deal predominantly with the writing process (including citing of sources) showed a high number of hits compared to the steps dealing with research (see graph 2). We will continue to monitor these findings and use the information to update and improve the ARC.

We have also created a survey, located on both the landing page and the final page of the tool, asking for demographic information as well as feedback on the usefulness of the ARC. We are currently in the process of adding an assessment tool to the final step, to be e-mailed to each user, which will give us additional information on how the ARC helped in the entire research process. 


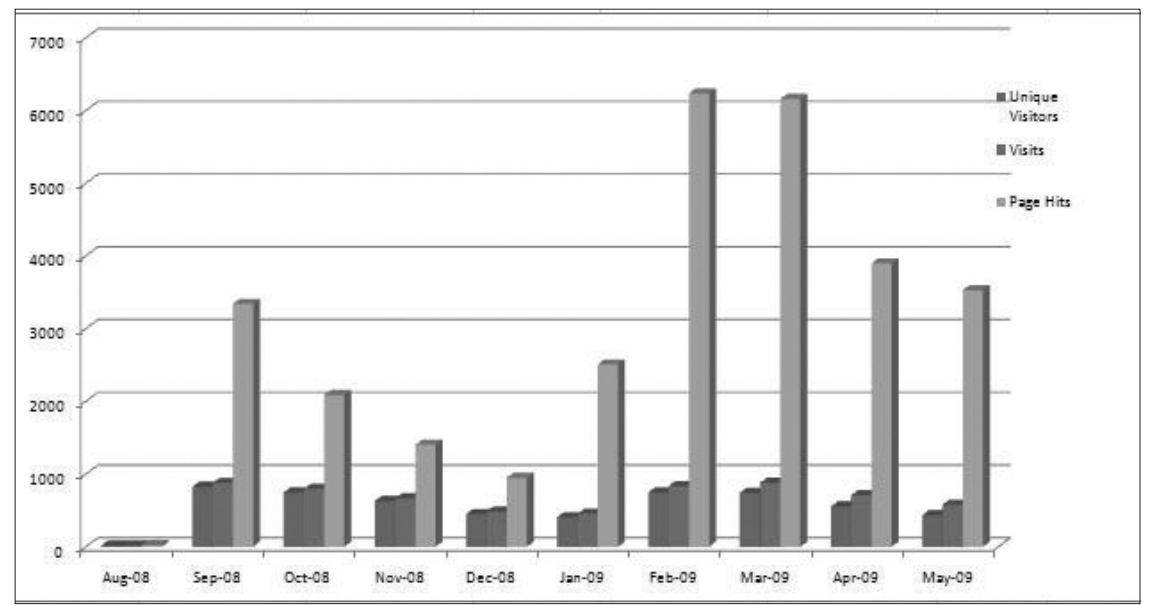

Graph 1. Hits to the ARC by month.

review, using a bibliographic management system, such as EndNote, and focusing on a more scholarly writing process.

Another potential project for the future is to create course- or subjectspecific ARCs in order to showcase resources and databases in particular

\section{A work in progress}

The ARC requires some routine maintenance, such as checking for broken or outdated links, replacing screenshots of databases and Web sites when necessary, and adding alternative text to describe images and multimedia for compliance with your own Web accessibility guidelines. Usage statistics and assessment results must be compiled, maintained, and evaluated. Publicity and promotion should be ongoing. Creating a unique ARC for your campus is initially very timeconsuming, but definitely worth it in the long run. It has been a rewarding and really fun experience, and has given us an op-

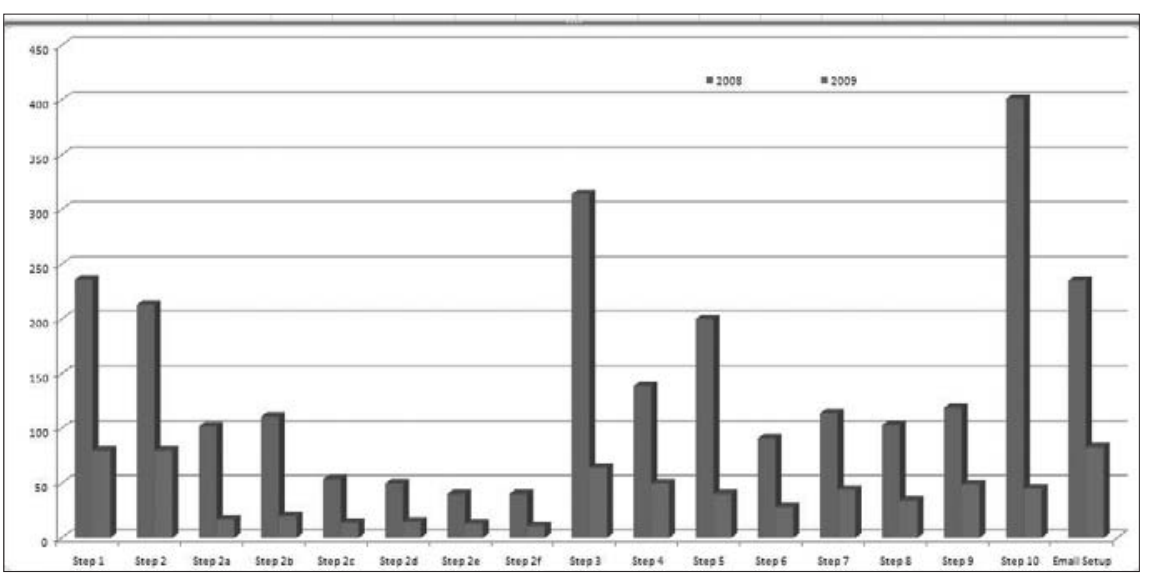

Graph 2. Hits to the ARC by step. portunity to reflect on who our students are, what they need, and what we do as professionals. We continue to receive very positive reactions from campus administration, faculty, and, of course, the students.

\section{Future plans}

We hope to create another research calculator aimed at master's and doctoral students, in which we will go into more depth with content of interest to the graduate student. This will address topics such as doing a literature areas, and to address discipline-specific research and writing issues.

Comments from students and faculty indicate that some users would like to see the information found within each step of the ARC be made available separately from the calculator tool. We are currently "unbundling" the steps so the content can be more easily incorporated into other tutorials, learning modules, faculty syllabi or assignments, and BlackBoard or other course management systems.

\section{Conclusion}

Anecdotal evidence from students in classes and at the reference desk indicates that they are impressed initially by the timetable/reminder features of the ARC, but later discover and appreciate the wealth of information (continues on page 468) 


\section{... there is a hesitancy to develop guidelines, which may restrict the creativity expressed in the portfolios; as a group, the librarians struggle to find a balance between standardization and creative freedom.}

inclusive, librarians going through the next review cycle will now be able to choose between Adobe Acrobat or LibGuides.

It seems that the discussion of which electronic "container" is used for the portfolios has kindled a more complex conversation about the content of the portfolios.

Many questions have been raised both in the survey responses and in other faculty discussions: How should evidence and narrative be linked? Should there be a standard template or specific stylistic guidelines to follow? What evidence should be narrated or compiled into a bulleted list? and What relationship do the portfolios have to the librarians' annual activity reports?

Although the librarians seek answers to these questions, there is a hesitancy to develop guidelines, which may restrict the creativity expressed in the portfolios; as a group, the librarians struggle to find a balance between standardization and creative freedom. However, articulated guidelines might provide the necessary structure to help make this process less work intensive.

For now, librarians who are more comfortable with a narrative format will likely choose Adobe Acrobat, while those librarians more conversant with principles of information architecture may gravitate toward using LibGuides. In some sense, the library is still standing at a crossroads with an eye in either direction. $\boldsymbol{n}$

\section{("Assignment Research Calculator" continues from page 459)}

found in each step. Our provost, library dean, Development Office, and other staff frequently promote the ARC to the campus and local community.

We feel the ARC has helped to foster awareness of the library and our many services to students, and we hope to be able to document this in the future through our feedback and assessment measures.

\section{Acknowledgments}

This project would not have been possible without funding from a CSU Information Literacy grant awarded to Monica Fusich from the California State University Chancellor's Office, CSU Fresno Foundation Grant Agreement no. 60040, and the technical expertise of Anish Dutta, graduate IT student, Instruction and Outreach Services Department.

\section{Notes}

1. Sourceforge.net, "Assignment Calculator," sourceforge.net/projects/assign-calc/ (accessed July 28, 2009).
2. The Assignment Research Calculator, csufresno.edu/library/ARC2/index.php (accessed July 28, 2009).

3. California State University-Fresno, Institutional Research, Assessment, and Planning, "IRAP Data and Research," www.csufresno. edu/irap/data/index.shtml (accessed July 28, 2009).

4. ACRL, "Introduction to Information Literacy," www.pla.org/ala/mgrps/divs /acrl/issues/infolit/overview/intro/index. cfm.

5. ACRL, "Information Literacy Competency Standards for Higher Education," www.ala.org/ala/mgrps/divs/acrl /standards/informationliteracycompetency. cfm.

6. About the ARC, csufresno.edu/library/ ARC2/about_us.shtml.

7. ACRL, "Information Literacy Competency Standards for Higher Education, Use of the Standards," www.ala.org/ ala/mgrps/divs/acrl/standards/ALA_print _layout_1_185693_185693.cfm\#useofst. $\boldsymbol{n}$ 